\title{
Testing of Maturity Methods for Concrete Quality Cured Using Various Temperatures
}

\author{
Ahmet Onur Pehlivan*, Ahmet Utku Yazgan* \\ *Department of Civil Engineering, Faculty of Engineering and Natural Sciences, Maltepe University, Istanbul, Turkey \\ (onurpehlivan@maltepe.edu.tr, utkuyazgan@maltepe.edu.tr) \\ $+$ \\ Ahmet Onur Pehlivan; Ahmet Utku Yazgan, Tel: +90 2166261050 \\ onurpehlivan@maltepe.edu.tr
}

Received: 11.11.2020 Accepted: 06.05.2021

\begin{abstract}
Maturity of concrete is a subject of utmost essence in all phases of a construction project that has to be dealt with care and accordingly important advantages may be gained with optimum predictions. In this study, concrete specimens at various strength classes were prepared to investigate on the effect of concrete class on two different maturity function given in literature. Procedures were handled in accordance with the prescriptions given in ASTM C 1074. Recommendations given in the same standard for standard cement type was discussed and convenience of two different maturity functions were analyzed. Important values obtained from mortar specimens tests were applied to maturity calculations of concrete mixtures and applicability of the methods were discussed. It is found that with the increasing concrete quality, for two extreme temperatures $\left(8\right.$ and $\left.25^{\circ} \mathrm{C}\right)$ in this study, important deviations in the results are observed. Results obtained from specimens cured at $36{ }^{\circ} \mathrm{C}$ were found to be significantly higher than specimens cured at $8{ }^{\circ} \mathrm{C}$ at higher maturity levels. Datum temperature and Q-values data obtained from mortar mixtures were applied to concrete specimens and it may be asserted that concrete specimens demonstrated good correlation with the findings of both maturity functions. Generally, it may be expressed that maturity functions behave well under normal temperatures however applicability at extreme temperatures should be limited.
\end{abstract}

Keywords- maturity; rapid curing; early strength; curing temperature; Nurse-Saul

\section{Introduction}

Maturity of concrete resembles a significant part of the common construction practice on site since large projects are generally tightly scheduled and any delay in any part of the work has to be minimized. Accelerated construction schedules of structures can be supplied with higher concrete quality that achieves high early age strength gain with respect to standard strength concrete. Henceforth, evaluation the early age strength evolution should be well established prior to any risk of improper construction phases. [1]

Given that concrete casting and formwork removal are of extreme importance when scheduling, duration of these phases of the construction should be estimated properly. Curing environment of the concrete involves several parameters including temperature, relative humidity and wind speed whereas temperature is the most assertive amongst them all [2].

Maturity method considers joined effect of both temperature and time on concrete strength development. With the available data of the temperature history, there are two different equations for estimating the maturity index [3]. The
Nurse Saul approach considers a linear relationship between temperature and rate of strength gain whereas Friesleben Hansen Pedersen approach infers that rate of strength gain conforms to exponential Arrhenius equation [4, 5]. The assumption of the linearity between rate of strength gain and temperature is given in Equation 1 which may be used to calculate temperature time factor. Datum temperature for specific materials and conditions should be estimated for computing the temperature time factor. Given that datum temperature may depend on any parameter that may interfere with the hydration process, especially types of cement and admixtures used gain significance [6, 7]. Brooks et al. [8] related an exponential and a hyperbolic model to strength evolution for different concrete classes with ordinary portland cement to obtain activation energy and results indicated that activation energy depends on the concrete strength growth model. Similar findings were also noted within different studies [9-11]. ASTM C1074 [12] suggests a standard value of $40.000 \mathrm{~J} / \mathrm{mol}$ for type I cement. However, differents standards such as Eurocode 2 [13], EHE-08 [14] and the Model code 2010 [15] address a value of $33000 \mathrm{~J} / \mathrm{mol}$ for ordinary concrete with no additional statement of the cement type. 
Nurse Saul recommended $-10{ }^{\circ} \mathrm{C}$ as datum temperature, however ASTM C1074 [12] has prescribed calculation of datum temperature by experimental work advocating that it differs due variety of materials in concrete composition. For computing equivalent age in FSB approach, another parameter called activation energy should be determined which corresponds to increasing temperature resistivity with increasing values. whereas 150x150x150 mm cubic steel molds were used for concrete compressive strength tests. All compressive strength test results were obtained from the average of triplicates.

As prescribed in ASTM C1074 [8], mortar mixtures were prepared with sand-to-cement ratios equal to the coarse aggregate-cement ratio in the concrete mixtures they represented. Main approach was to provide a compressive

Table 1. Concrete and mortar mixture compositions.

\begin{tabular}{|c|c|c|c|c|c|c|c|}
\hline \multicolumn{4}{|c|}{ Concrete Mixture Proportions $\left(\mathrm{kg} / \mathrm{m}^{3}\right)$} & \multicolumn{4}{c|}{ Mortar Mixture Proportions $\left(\mathrm{kg} / \mathrm{m}^{3}\right)$} \\
\hline & C25 & C35 & C45 & & M25 & M35 & M45 \\
\hline Cement & 254 & 276 & 258 & Cement & 397 & 443 & 435 \\
\hline Water & 208 & 193 & 142 & Water & 324 & 310 & 236 \\
\hline $0-5 \mathrm{~mm}$ & 977 & 988 & 980 & $0-5 \mathrm{~mm}$ & 1495 & 1492 & 1705 \\
\hline $15-25 \mathrm{~mm}$ & 500 & 488 & 527 & SP & 0 & 0 & 1.83 \\
\hline SP & 0 & 0 & 1.09 & W/C & 0.82 & 0.70 & 0.55 \\
\hline W/C & 0.82 & 0.70 & 0.55 & F.Agg./Cement & 3.77 & 3.37 & 3.92 \\
\hline C.Agg/Cement & 3.76 & 3.38 & 3.91 & & & & \\
\hline Slump (mm) & 120 & 115 & 120 & & & & \\
\hline
\end{tabular}

$$
M(t)=\sum\left(T_{a}-T_{0}\right) \Delta t
$$

where $\mathrm{M}=$ maturity index $\left({ }^{\circ} \mathrm{C} \mathrm{h}\right.$ or ${ }^{\circ} \mathrm{C}$ day); $\mathrm{T}_{\mathrm{a}}=$ average concrete in duration $\Delta \mathrm{t}\left({ }^{\circ} \mathrm{C}\right), \mathrm{T} 0=$ datum temperature, time (hour or day), $\Delta \mathrm{t}=$ duration (hour or day) are represented.

The other maturity function is facilitated to estimate equivalent age at a specified temperature as given in Eq. 2.

$$
t_{e}=\sum e^{-\frac{E}{R}\left(\frac{1}{T_{a}}-\frac{1}{T_{S}}\right)} \Delta t
$$

where te $=$ equivalent age at a specified temperature $T_{\mathrm{s}}$ (hour or day), $\mathrm{Q}=$ activation energy divided by the gas constant, $(\mathrm{K}), \mathrm{T}_{\mathrm{a}}=$ average temperature of concrete in duration $\Delta \mathrm{t}(\mathrm{K}), \mathrm{T}_{\mathrm{s}}=$ specified temperature $(\mathrm{K}), \Delta \mathrm{t}=$ duration (hour or day).

In this study, strength evaulation of different classes of concrete were conducted to monitor the reliability of the two suggested maturity functions. Thus, maturity functions may be applied to construction sector with proper estimation of strength over maturity that would really help the concrete practitioners in casual construction works.

\section{Experimental Study}

In this study, CEM-I PC 42.5R Portland cement acquired from Akcansa cement factory was used as binder. River sand (0-5 $\mathrm{mm})$ and coarse crushed aggregates with two different sizes (5-15 mm and 15-25 mm) were used. Superplasticizer (BASF Rheoubuild 1000) was also used to have similar workability in different mixtures. Three different mortar and concrete mixtures with a total of 6 mixtures were used. $50 \times 50 \times 50 \mathrm{~mm}$ steel molds were used for mortar mixes strength versus age relation for mortar specimens cured in water tanks with three different temperatures $\left(8,25\right.$ and $\left.36{ }^{\circ} \mathrm{C}\right)$ and use the obtained data on the actual concrete specimen curing progress. For 25 and $36^{\circ} \mathrm{C}$ curing, separate water tanks were heated up to given temperature, whereas specimens stored in $8^{\circ} \mathrm{C}$ water tanks were placed in refrigerators with its own thermostat system.

Also concrete specimens were molded in three different concrete compositions to correlate with the mortar specimens

Table 2. Compressive strength of different concrete mixtures cured at $25^{\circ} \mathrm{C}$.

\begin{tabular}{|c|c|c|c|}
\hline \multicolumn{4}{|c|}{ Concrete Classes } \\
\hline $\begin{array}{c}\text { Time } \\
\text { (day) }\end{array}$ & $\begin{array}{c}\mathrm{C} 25 \\
(\mathrm{MPa})\end{array}$ & $\begin{array}{c}\mathrm{C} 35 \\
(\mathrm{MPa})\end{array}$ & $\begin{array}{c}\mathrm{C} 45 \\
(\mathrm{MPa})\end{array}$ \\
\hline 1 & 10.18 & 15.38 & 15.07 \\
\hline 3 & 20.15 & 22.50 & 27.61 \\
\hline 7 & 25.90 & 29.00 & 30.50 \\
\hline 14 & 27.08 & 31.70 & 35.00 \\
\hline 28 & 28.85 & 34.55 & 38.84 \\
\hline 90 & 33.70 & 40.00 & 43.30 \\
\hline
\end{tabular}

and finally to conclude that the approach is applicable or not. All mixture compositions are given in Table 1.

\section{Results and Discussion}

Compressive strength results of concrete specimens with different concrete classes at $25^{\circ} \mathrm{C}$ curing temperature are given in Table 2. These experimental compressive strength results were used to compare with the maturity results calculated with the parameters obtained from the experimental data acquired from mortar mixtures results. 
Compressive strength results of mortar specimens with different compositions representing the concrete classes attributed to concrete specimens are given in Figure 1. All mortar specimens were crushed at different time intervals (1, $2,4,8,16,32$ ) which were given in ASTM C1074 [8], however concrete specimens were tested at standard time intervals $(1,3,7,14,28,90$ days). According to compressive strenght results of mortar specimens in Figure 1, M25 and M35 series mortars were found to have distinct strength evolution for each curing temperature whereas M45 specimens experienced closer results for 25 and $36{ }^{\circ} \mathrm{C}$ temperatures and cross over effect between curing temperatures were noticed for M45 series only.

\subsection{Determination of datum temperature and activation} energy

Strength versus age data were analyzed to estimate the relationship between the rate constant $(\mathrm{k})$ and the curing temperatures. Data was fitted to following equation (Equation 3 ) and k-values were determined by using solver function in Microsoft Excel minimizing the sum of the square of errors by changing the values of the parameters $\mathrm{Su}, \mathrm{k}$ and $\mathrm{t} 0$.
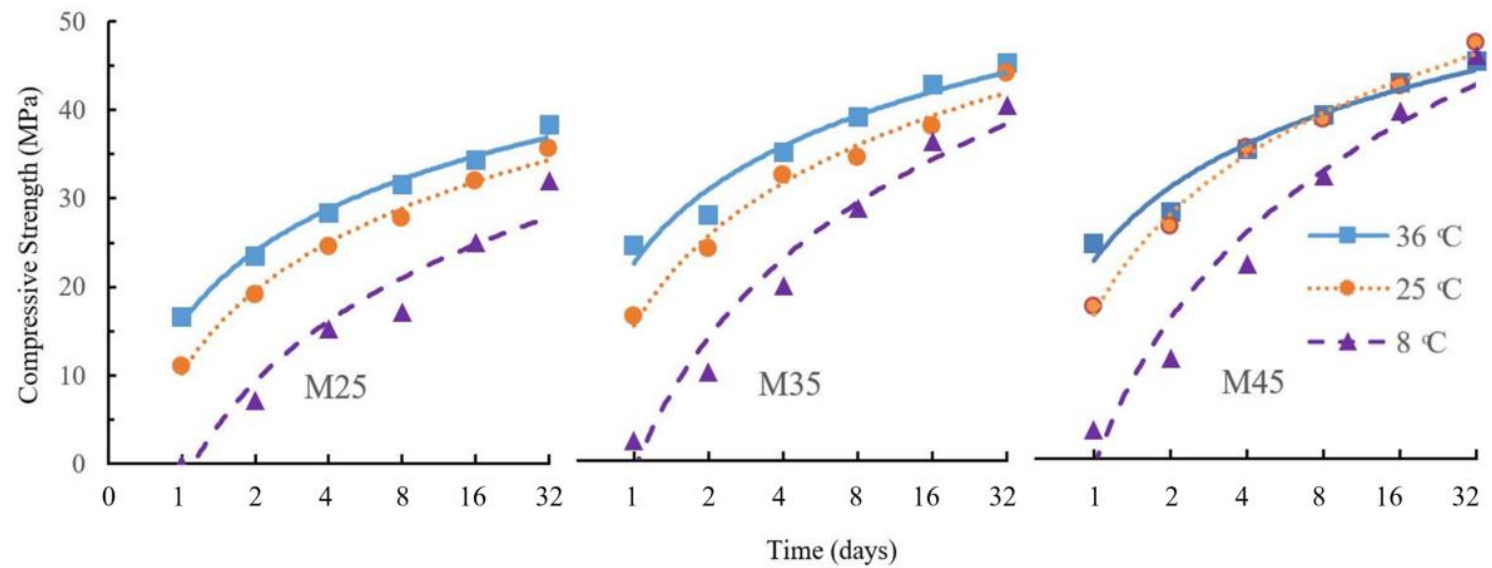

Figure 1. Compressive strength results of mortar specimens cured at different temperatures.

(a)

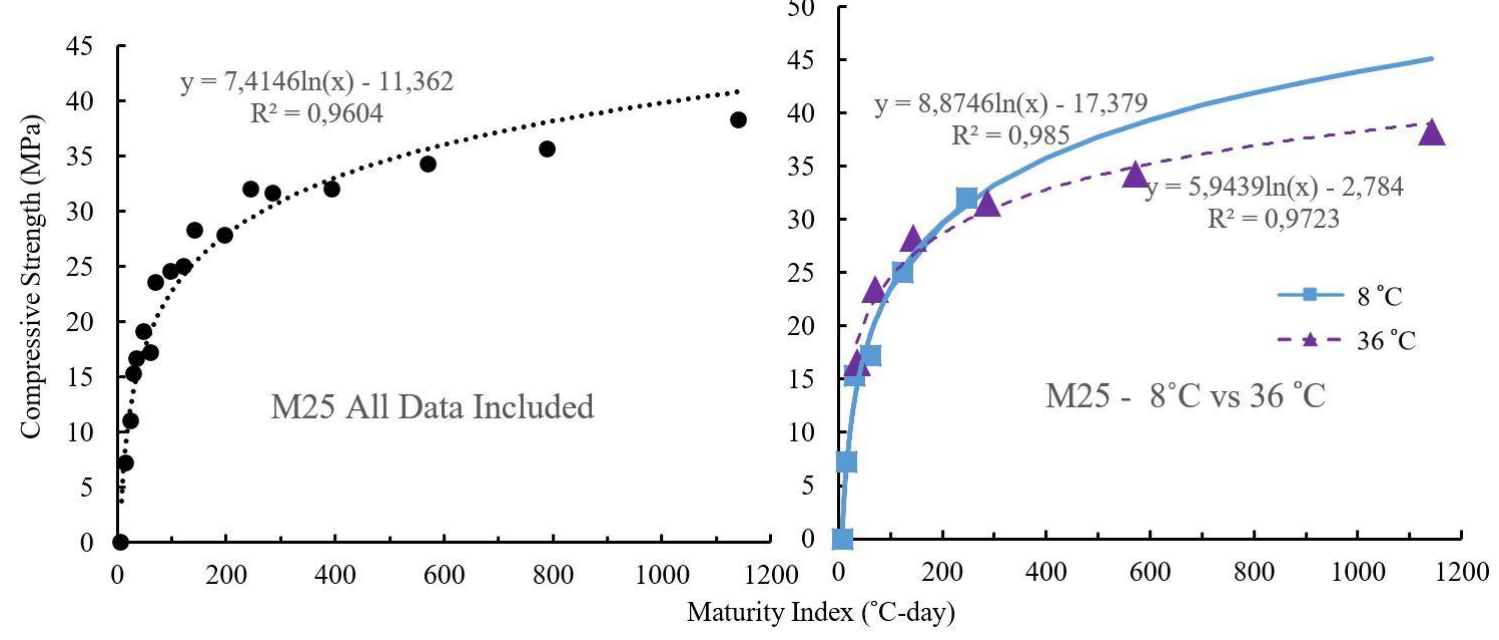

Figure 2. Compressive strength - maturity relationships (a) for all test results of M25 mixes (b) comparison of 8 and $36{ }^{\circ} \mathrm{C}$ test results. 


$$
S=S_{u} \frac{k\left(t-t_{0}\right)}{1+k\left(t-t_{0}\right)}
$$

When (a) segments of Figs. 2, 3 and 4 were analyzed, it was seen that the findings with respect to Nurse-Saul maturity

Table 3. Datum temperature, Q-value and k-values.

\begin{tabular}{|c|c|c|c|c|c|c|c|c|c|}
\hline Mortar type & \multicolumn{3}{|c|}{ M25 } & \multicolumn{3}{c|}{ M35 } & \multicolumn{3}{c|}{ M45 } \\
\hline Curing Temperature $\left({ }^{\circ} \mathrm{C}\right)$ & 8 & 25 & 36 & 8 & 25 & 36 & 8 & 25 & 36 \\
\hline k-value $(1 /$ day $)$ & 0.17 & 0.50 & 0.75 & 0.23 & 0.60 & 0.86 & 0.22 & 0.64 & 0.96 \\
\hline Datum Temperature $\left({ }^{\circ} \mathrm{C}\right)$ & \multicolumn{3}{|c|}{0.3} & \multicolumn{3}{c|}{-2.17} & \multicolumn{3}{c|}{0} \\
\hline Q-value & \multicolumn{3}{c|}{476123} & \multicolumn{3}{c|}{4669} \\
\hline
\end{tabular}

Subsequent to determination of k-values, datum temperature values were obtained by plotting the rate constant value to water bath temperatures and fitting the best trendline to the three values and finally obtaining the value of the intercept with the temperature axis. Q-values were obtained by plotting the natural logarithms of the $\mathrm{k}$-values versus the reciprocal temperatures (in kelvin) and fitting the best trendline of the three values and obtaining the slope of the curve. Datum temperature, Q-value and k-values can be viewed in Table 3. These findings were noted to be used further in maturity evolution according to both Nurse-Saul and equivalent age function.

\subsection{Nurse Saul Maturity Function}

Nurse-Saul functions were established for all three mortar mixtures to investigate the effect of concrete quality on the accuracy of compressive strength estimation. Datum temperature values and temperature time factor functions were given in Table 3. By using the data in Table 4, Figs. 2, 3 and 4 were determined. When these figures are inspected it may be expressed that especially for lower concrete quality, values were found to be extremely fitting to the Nurse-Saul maturity proposal whereas with the increasing concrete quality, deviation in the results also increase. method were applicable for this type of normal cement whereas it should also be noted that the correlation between the findings at different maturity indices was not this much apparent with respect to higher concrete quality specimens. It may be figured out that with the decreasing $\mathrm{R} 2$ value, correlation between the findings were decreasing.

When (b) segments of Figs. 2, 3 and 4 demonstrated the differences between two extreme curing temperatures for this study when Nurse-Saul maturity functions were adapted. Both temperature findings seemed to be quite correlated with the

Table 4. Nurse-Saul Functions

\begin{tabular}{|l|c|c|}
\hline & $\begin{array}{c}\text { Datum Temperature } \\
\left({ }^{\circ} \mathrm{C}\right)\end{array}$ & Nurse-Saul Functions \\
\hline M25 & 0.3 & $\mathrm{M}=\Sigma(\mathrm{T}-0.3) \Delta \mathrm{t}$ \\
\hline M35 & -2.17 & $\mathrm{M}=\Sigma(\mathrm{T}+2.17) \Delta \mathrm{t}$ \\
\hline M45 & 0 & $\mathrm{M}=\Sigma(\mathrm{T}-0) \Delta \mathrm{t}$ \\
\hline
\end{tabular}

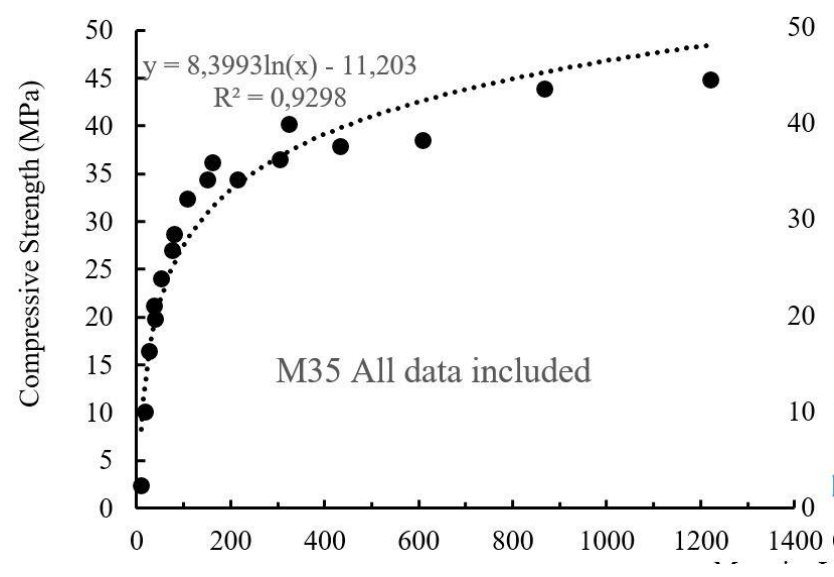

(a)

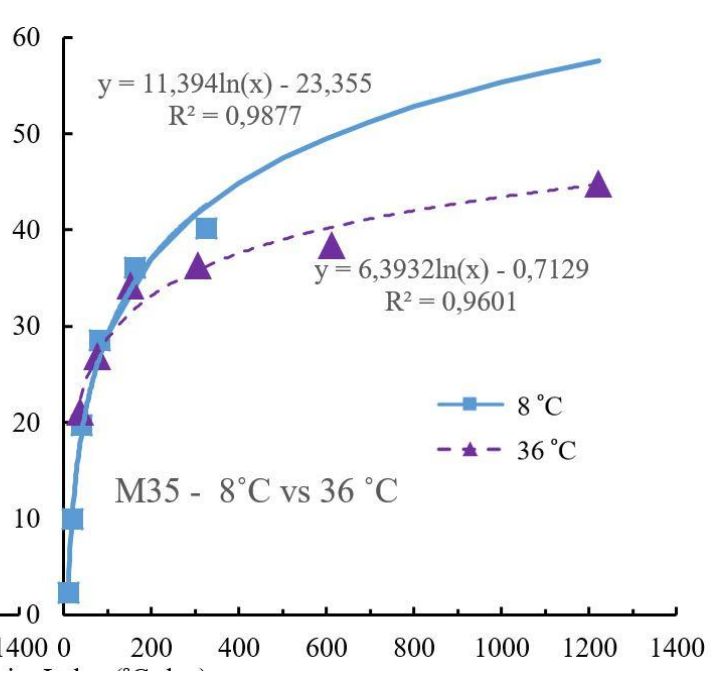

(b)

Figure 3. Compressive strength - maturity relationships (a) for all test results of M35 mixes (b) comparison of 8 and $36{ }^{\circ} \mathrm{C}$ test results. 


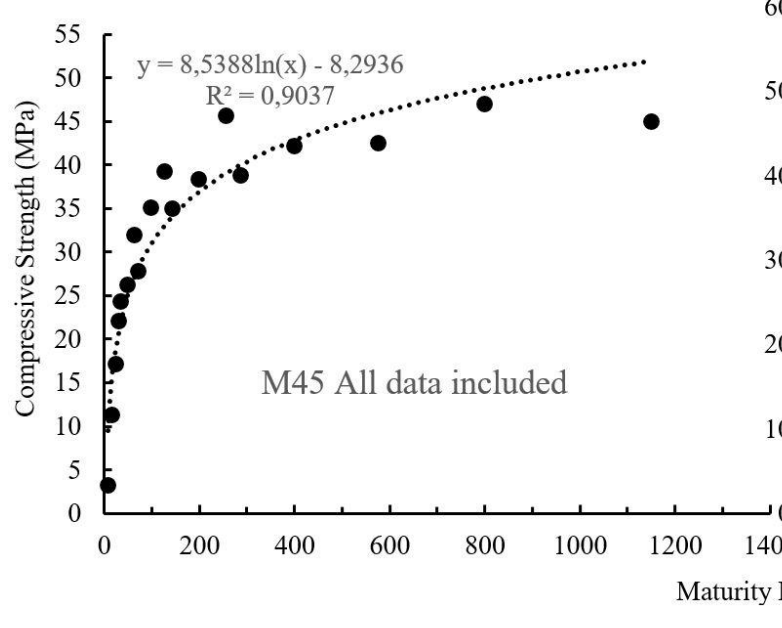

(a)

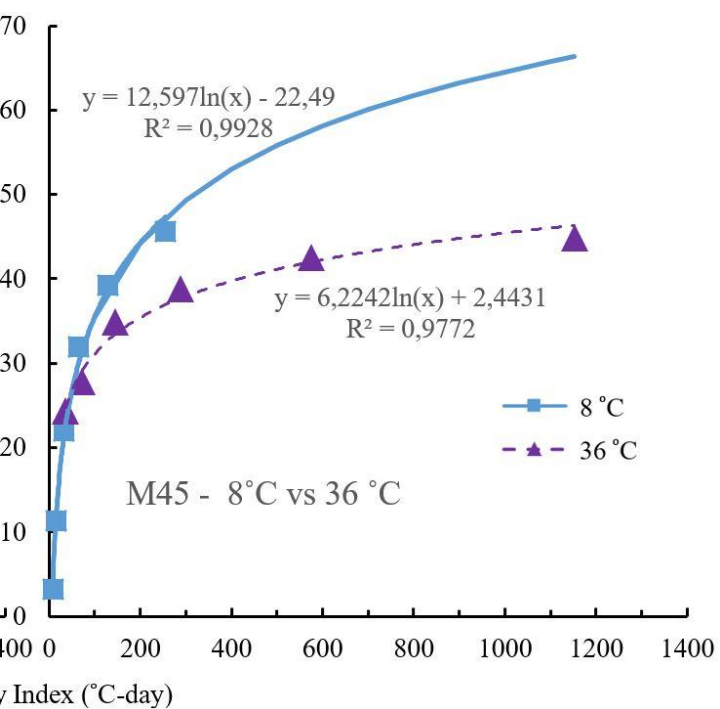

(b)

Figure 4. Compressive strength - maturity relationships (a) for all test results of M45 mixes (b) comparison of 8 and $36^{\circ} \mathrm{C}$ test results.

Table 5. Equivalent age functions and activation energies for mortar mixtures

\begin{tabular}{|c|c|c|}
\hline $\begin{array}{c}\text { Mortar } \\
\text { Mixture }\end{array}$ & $\begin{array}{c}\text { Activation } \\
\text { Energy } \\
(\mathrm{J} / \mathrm{mol})\end{array}$ & Equivalent Age Function \\
\hline M25 & 39564 & $t_{e}=\sum e^{-\frac{39564}{8.314}\left(\frac{1}{T_{a}}-\frac{1}{T_{S}}\right)} \Delta t$ \\
\hline M35 & 34262 & $t_{e}=\sum e^{-\frac{34262}{8.314}\left(\frac{1}{T_{a}}-\frac{1}{T_{S}}\right)} \Delta t$ \\
\hline M45 & 38799 & $t_{e}=\sum e^{-\frac{38799}{8.314}\left(\frac{1}{T_{a}}-\frac{1}{T_{S}}\right)} \Delta t$ \\
\hline
\end{tabular}

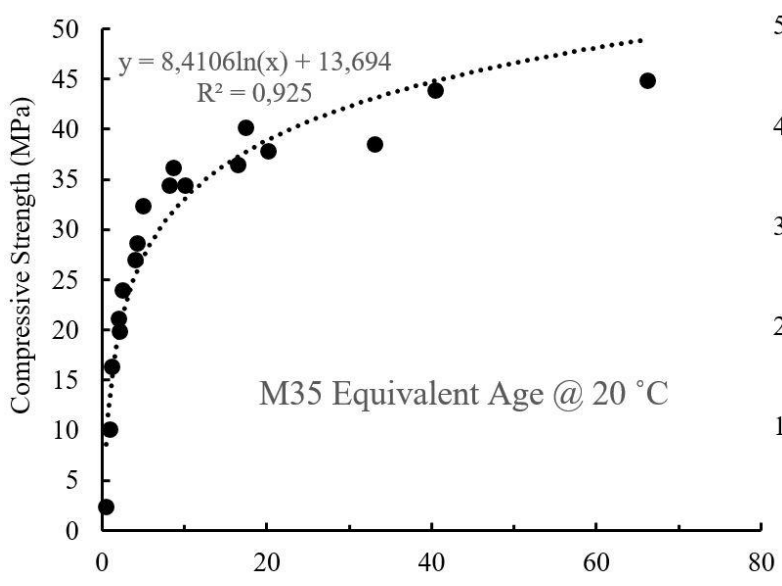

(a) findings within the same curing temperature however when different temperature levels were inspected individually, the differences in compressive strength at the same maturity index gave clue about the adaptability of the method applied.

For all 3 concrete classes, when two best fitting logarithmic curves derived from the results obtained from two extreme temperatures, it is seen that higher temperature curve crosses the lower temperature curve and increases with decreasing rate. On the other hand, lower temperature curve also increases but with higher decreasing rate with respect to higher temperature curve. Eventually with the distinction between the decreasing rates, two curves differ from each other and differences between two curves become more visible with the increasing maturity index.

For all specimen classes, two curves moved quite similar to each other at lower maturity indices and difference between

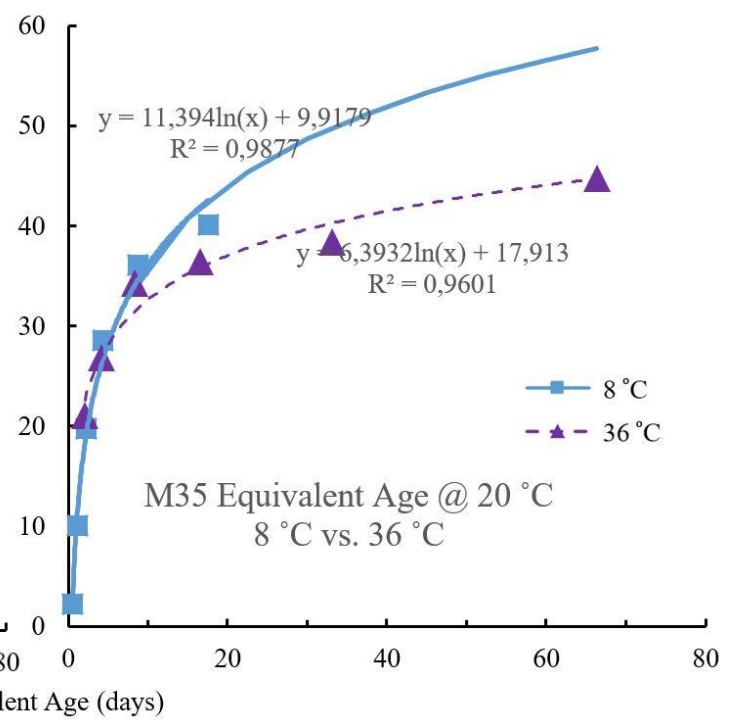

(b)

Figure 5. Compressive strength vs. equivalent age for M25 specimens (a) all specimens (b) extreme temperatures individually. 


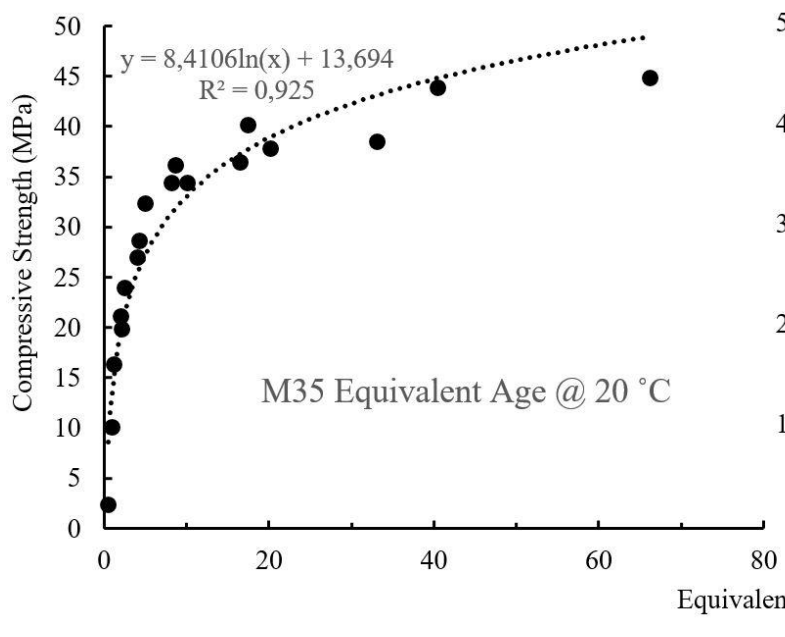

(a)

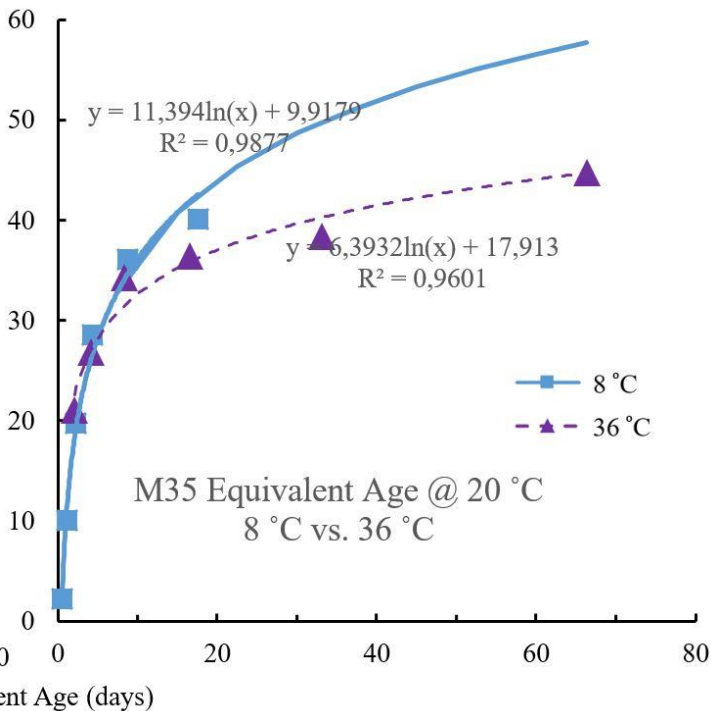

(b)

Figure 6. Compressive strength vs. equivalent age for M35 specimens (a) all specimens (b) extreme temperatures individually

these curves became more apparent at higher maturity indices however for higher quality concretes, these distinctions between two curves were more clear and meaningful. Henceforth, with the increasing concrete quality it was seen that applicability of Nurse-Saul maturity method lost significance. The difference between two curves of different temperatures were significantly high, expressing that this method was not applicable for high strength concrete classes like C45 which were being used substantially for every standard structures in last decades.

\subsection{Equivalent Age Function}

In earlier studies, equivalent age function is generally accepted as a more accurate and applicable method since it considers maturity evolution as a nonlinear relationship unlike Nurse-Saul method. Activation energy is calculated as Qvalue times gas constant $(\mathrm{R})$ which also is described in Section 3.1.

Equivalent age functions of the three different classes of mortar mixtures were tabulated with the activation enegy values and how they were implemented in the equivalent age

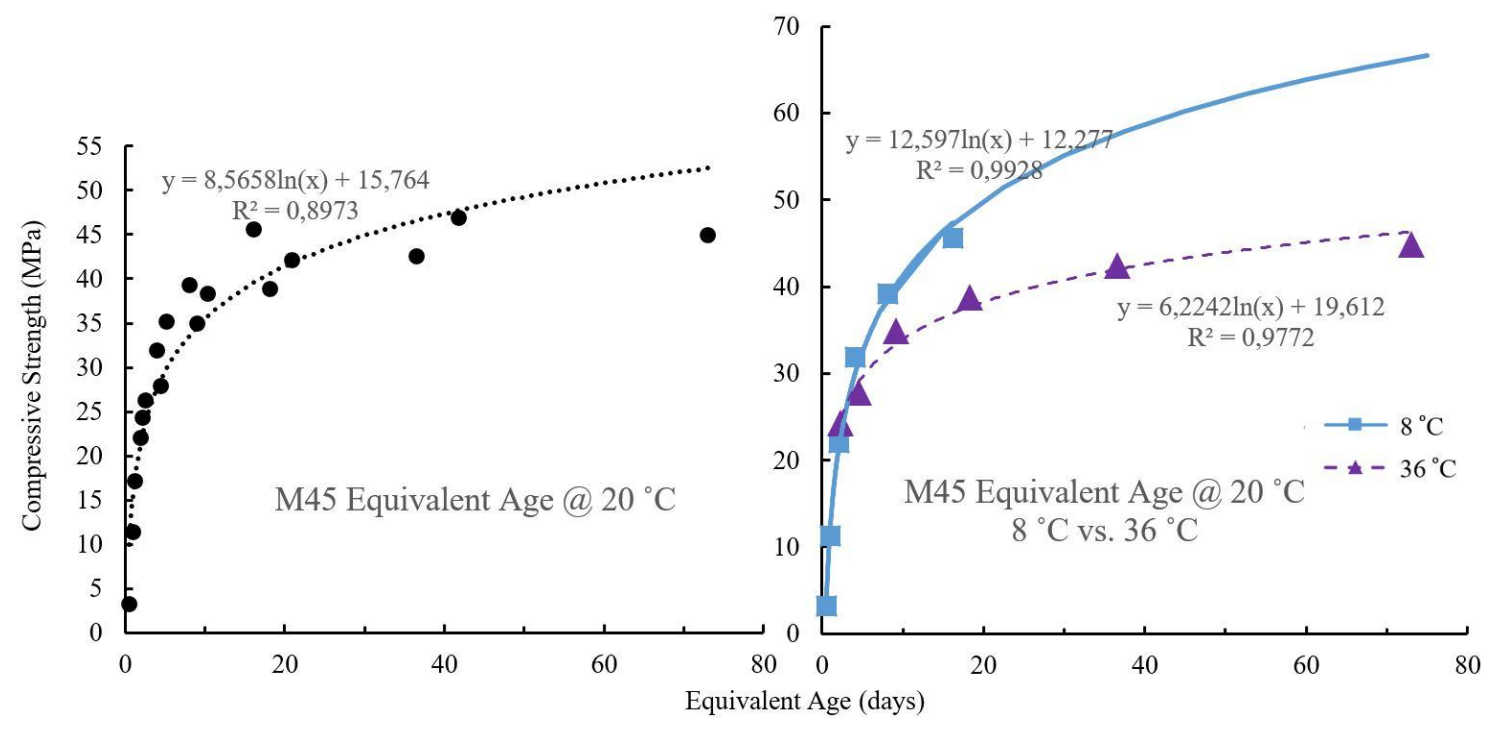

(a)

(b)

Figure 7. Compressive strength vs. equivalent age for M45 specimens (a) all specimens (b) extreme temperatures individually 


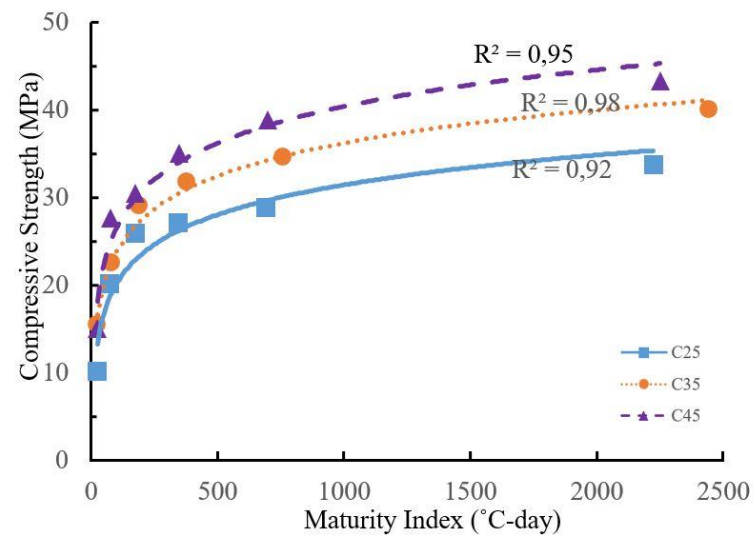

(a)

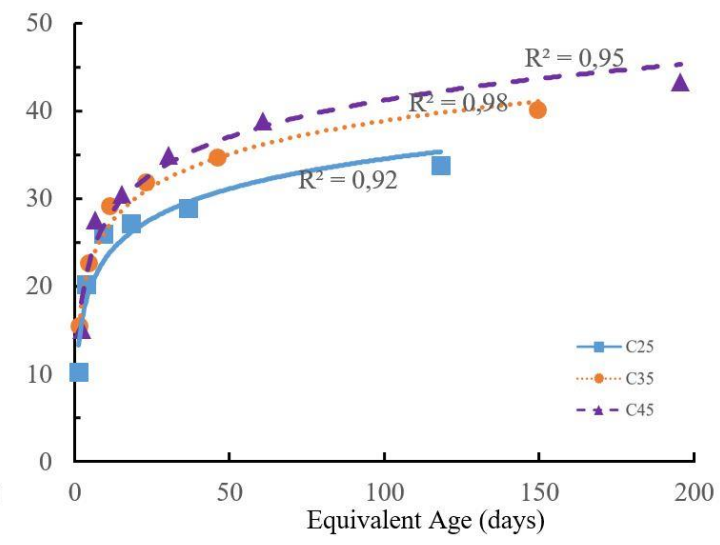

(b)

Figure 8. Compressive strength analysis concrete mixtures (a) versus maturity index (b) equivalent age.

function is given in Table 5. Activation energy was implemented in the equations and also specified temperature $\left(\mathrm{T}_{\mathrm{s}}\right)$ was chosen as $20{ }^{\circ} \mathrm{C}$ in all equivalent age function analyses.

As described in Nurse-Saul function, equivalent age functions were also analyzed characterizing the accordance of the findings to each other. When all specimens are investigated together, results seemed to be in good correlation with each other likewise Nurse-Saul function findings. Seemingly, correlation of the compressive results with increasing equivalent age was found to be decreasing with increasing concrete quality. This may be easily recognized by comparing $\mathrm{R}^{2}$ results of different classes.

Figures $5 b, 6 b$ and $7 b$ display compressive strength equivalent age relationship of two extreme curing temperatures at a specified temperature of $20^{\circ} \mathrm{C}$. At very low equivalent age, curing temperatures created similar results, compressive strengths of these different curing temperatures were the same at an equivalent age of 9.41 MPa for M25, 4.95 MPa for M35 and 3.16 MPa for M45 specimens. These results showed that higher concrete quality specimens experience higher strength gain at similar equivalent age under higher curing temperature.

For higher concrete quality, it could be easily seen that difference in the amount of strength gain between two curing temperatures displayed significance. If fitted curve equations were considered at a level of 60 days of equivalent age, variation between the curing temperatures was found $14 \%$ for $\mathrm{M} 25,28 \%$ for M35 and 42\% for M45. If same analyses also were applied for Nurse-Saul maturity method, very similar results were viewed. Since M45 specimens showed high difference between two curing temperature results, it could be expressed that equivalent age maturity method was not applicable for higher strength classes and some improvements had to be asserted to minimize this difference.

\subsection{Evaluation of maturity functions on concrete specimens}

Concrete specimens that were represented by mortar specimens were also analyzed with the datum temperature and activation energy obtained from analyses in Section 3.1. In Fig. 8, compressive strength versus maturity index and equivalent age data were given for three different concrete classes.

In Fig. 8, all concrete classes' compressive strength results seemed to be highly correlated. R2 values are higher than $90 \%$ for all specimens for both maturity functions. When two maturity functions are compared, it could be expressed that equivalent age function had shown better results. Equivalent age function was found to have better results when compared to Nurse-Saul function.

\section{Conclusion}

In this study, comparisons of compressive strength gains were carried out with the increasing maturity method indices like temperature time factor and equivalent age factor with different mixture qualities that use the same cement as the only binder. Purpose was to analyze the effeciency of both mixtures in 3 different concrete classes and monitor the net differences in 3 distinct curing temperatures. All experimental work has been conducted according to specifications given in ASTM C1074. According to findings, both maturity methods create good results with high correlation to some extent since with increasing concrete quality results showed higher deviations. Moreover, higher interest should be drawn to strength differences between two extreme curing temperatures implemented in this study $\left(8\right.$ and $\left.36{ }^{\circ} \mathrm{C}\right) .42 \%$ difference in compressive strength was observed at the same level of equivalent age for highest concrete quality specimens and 44 $\%$ difference was detected for at the same level of maturity index when Nurse-Saul method was applied. Thus it may be added that strength development should be developed in nonlinear basis rather linear relationships. As a general conclusion, these findings express that both maturity functions experience difficulties when curing temperature was far from standard values. 


\section{References}

[1] S. J. Barnett, M. N. Soutsos, J. H. Bungey, and S. G. Millard, "Fast-track construction with slag cement concrete: adiabatic strength development and strength prediction", ACI Materials Journal, vol. 104, no. 4, pp. 388-396, 2007. (Article)

[2] T. Kim and K. L. Rens, "Concrete maturity method using variable temperature curing for normal and high-strength concrete. I: Experimental study", Journal of Materials in Civil Engineering, Vol. 20, No. 12, pp. 727-734, 2008. (Article)

[3] C. H. Lee and K. C. Hover, "Influence of datum temperature and activation energy on maturity strength predictions", ACI Materials Journal, Vol. 112, No. 6, pp.781790, 2015. (Article)

[4] A. G. A Saul, "Principles Underlying the Steam Curing of Concrete at Atmospheric Pressure", Magazine of Concrete Research, Vol. 2, No. 6, pp. 127-140, 1951. (Article)

[5] P. Freiesleben Hansen, and J. Pedersen, "Maturity computer for controlled curing and hardening of concrete", Nordisk Betong, Vol 1, pp.19-34, 1975. (Article)

[6] N. J. Carino and R. C. Tank, "Maturity functions for concretes made with various cements and admixtures", ACI Materials Journal, Vol. 89, pp. 188-196, 1992. (Article)

[7] R. C. Tank and N. J. Carino, "Rate constant functions for strength development of concrete", ACI Materials Journal, Vol. 88, No. 1, pp.74-83, 1991. (Article)

[8] A. G. Brooks, A. K. Schindler and R. W. Barnes, "Maturity method evaluated for various cementitious materials", J. Mater. Civil Eng., Vol. 19, No.12, pp. 1017-1025, 2007. (Article)

[9] S. A. Wade, J. M. Nixon, A. K. Schindler and R.W. Barnes, "Effect of temperature on the setting behavior of concrete", J. Mater. Civil Eng., pp. 214-222, 2010. (Article)

[10] R.C.A. Pinto and A.K. Schindler, "Unified modeling of setting and strength development", Cement and Concrete Research, Vol. 40, pp. 58-65, 2010. (Article)

[11] J. L. Poole, K.A. Riding, K.J. Folliard, M. C. G. Juenger, A.K. Schindler, "Methods for calculating activation energy for Portland cement", ACI Materials Journal, pp. 86-94, 2007. (Article)

[12] ASTM C 1074, Standard practice for estimating concrete strength by the maturity method, ASTM, 2019. (Standards and Reports)

[13] Eurocode No. 2, Design of concrete structures. Part 1: General rules and rules for buildings, 1991. (Standards and Reports)

[14] Ministry of public work and transport., Instructions on structural concrete. EHE. Madrid; 2008. (Standards and Reports)

[15] FIB Model Code 2010, First complete draft, Vol. 1, 2010. (Standards and Reports) 